ARTICLE

\title{
Multilayer stabilization for fabricating high-loading single-atom catalysts
}

\author{
Yazhou Zhou (i) 1,2,7, Xiafang Tao ${ }^{1,2,7}$, Guangbo Chen (1) ${ }^{3}$, Ruihu Lu (D) ${ }^{4}$, Ding Wang ${ }^{1}$, Ming-Xi Chen (D) ${ }^{5}$, \\ Enquan Jin', Juan Yang ${ }^{2}$, Hai-Wei Liang (DD ${ }^{5}$, Yan Zhao ${ }^{4}$, Xinliang Feng (1D ${ }^{3}$, Akimitsu Narita ${ }^{1,6 凶} \&$ \\ Klaus Müllen (1D ${ }^{1 \times}$
}

Metal single-atom catalysts (M-SACs) have emerged as an attractive concept for promoting heterogeneous reactions, but the synthesis of high-loading M-SACs remains a challenge. Here, we report a multilayer stabilization strategy for constructing M-SACs in nitrogen-, sulfur- and fluorine-co-doped graphitized carbons ( $\mathrm{M}=\mathrm{Fe}, \mathrm{Co}, \mathrm{Ru}, \mathrm{Ir}$ and $\mathrm{Pt}$ ). Metal precursors are embedded into perfluorotetradecanoic acid multilayers and are further coated with polypyrrole prior to pyrolysis. Aggregation of the metals is thus efficiently inhibited to achieve M-SACs with a high metal loading ( $16 \mathrm{wt} \%)$. Fe-SAC serves as an efficient oxygen reduction catalyst with half-wave potentials of 0.91 and $0.82 \mathrm{~V}$ (versus reversible hydrogen electrode) in alkaline and acid solutions, respectively. Moreover, as an air electrode in zinc-air batteries, Fe-SAC demonstrates a large peak power density of $247.7 \mathrm{~mW} \mathrm{~cm}^{-2}$ and superior long-term stability. Our versatile method paves an effective way to develop high-loading M-SACs for various applications.

\footnotetext{
${ }^{1}$ Max Planck Institute for Polymer Research, 55128 Mainz, Germany. ${ }^{2}$ School of Materials Science and Engineering, Jiangsu University, Zhenjiang, Jiangsu 212013 , China. ${ }^{3}$ Center for Advancing Electronics Dresden (Cfaed) and Faculty of Chemistry and Food Chemistry, Technische Universität Dresden, 01062 Dresden, Germany. ${ }^{4}$ State Key Laboratory of Silicate Materials for Architectures, International School of Materials Science and Engineering, Wuhan University of Technology, Wuhan, Hubei 430070, China. ${ }^{5}$ Hefei National Laboratory for Physical Sciences at the Microscale, Department of Chemistry, University of Science and Technology of China, Hefei 230026, China. ${ }^{6}$ Organic and Carbon Nanomaterials Unit, Okinawa Institute of Science and Technology Graduate University,

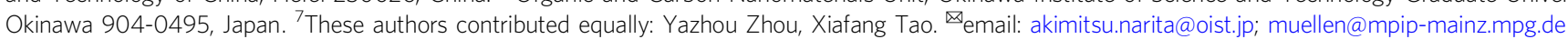


eterogeneous metal catalysts play a vital role in industrial chemical synthesis, sustainable energy conversion devices and advanced biotechnologies ${ }^{1-4}$. A key concept for catalyst design is the atomic dispersion of metals on solid supports, leading to so-called single-atom catalysts (SACs $)^{5,6}$. Single-metal atoms hold promise for unique activity, selectivity, and atom utilization efficiency ${ }^{7,8}$. The supports can also change the electronic structures of the single atoms. SACs can thus provide versatile pathways for efficient mass and charge transport, and bridge the gap between homogeneous and heterogeneous catalysis $^{9,10}$.

There is ample literature evidence that the single-atom character $^{11,12}$, coordination environment ${ }^{13,14}$, metal-support interaction $^{15-17}$, and metal loading are important factors that determine the catalytic performance of $\mathrm{SACs}^{18}$. Increasing the metal loading while maintaining the atomic dispersion should be a promising strategy to further enhance catalytic performance ${ }^{19}$. However, the surface free energy of metals increases significantly with decreasing particle size, leading to the successive formation of clusters and nanoparticles with a lower activity ${ }^{5}$. Various concepts have been proposed to fabricate SACs through the stabilization of metal atoms on supports ${ }^{20,21}$, such as defect engineering of metal hydroxide and oxide supports ${ }^{22}$, spatial confinement in zeolites ${ }^{23,24}$, fabrication of metal-organic frameworks (MOFs) or covalent-organic frameworks ${ }^{25-27}$, and utilization of strong interactions between metal species and coordinating heteroatoms (e.g., nitrogen $(\mathrm{N})$, oxygen $(\mathrm{O})$, and sulfur $(\mathrm{S}))^{28-30}$. For example, Zhang et al. ${ }^{20}$ demonstrated that defects in nickel hydroxide $\left(\mathrm{Ni}(\mathrm{OH})_{x}\right)$ could serve as 'traps' to stabilize metal species, achieving a Pt loading much higher than that attained by using defect-free $\mathrm{Ni}(\mathrm{OH})_{x}$. Li et al. ${ }^{31}$ employed zeolitic imidazolate frameworks (ZIFs), a class of MOFs as anchoring sites, to stabilize single manganese $(\mathrm{Mn})$ atoms with a Mn content of $3.03 \mathrm{wt} \%$. However, these approaches still do not rigorously exclude metal aggregation. This drawback is especially severe when using high amounts of metal precursors and hightemperature pyrolysis, because acidic etching processes to remove the non-single metallic species are required ${ }^{32}$. These procedures not only make the control of metal loading challenging but also randomly create single atomic active sites on the supports, resulting in low reproducibility ${ }^{33}$. Moreover, most of the reported SACs have very low metal loading, so robust approaches for fabricating SACs with high metal loading (>2 wt\%) have remained elusive ${ }^{19}$

Here we report a uniform protocol for multilayer stabilization to produce high-loading M-SACs supported by N, S, and fluorine (F)-co-doped porous graphitized carbon (M-SA-NSFC). Our concept comprises confinement of organometallic precursors (OMs) inside perfluorotetradecanoic acid (PFTA) bilayers that are further coated with polypyrrole (Ppy) layers prior to a final pyrolysis process. The confinement by PFTA and Ppy multilayers can efficiently prevent OMs from migrating during the pyrolysis process, resulting in the coordination of isolated metal atoms with $\mathrm{N}$ atoms in porous graphitized carbon. This method enables the synthesis of various M-SACs with a high loading of up to $\sim 16 \mathrm{wt} \%$, including both non-precious and noble metals of iron $(\mathrm{Fe})$, cobalt $(\mathrm{Co})$, ruthenium $(\mathrm{Ru})$, iridium ( $\mathrm{Ir}$ ), and platinum $(\mathrm{Pt})$. Furthermore, the electrocatalytic oxygen reduction reaction (ORR), a crucial process in next-generation energy storage and conversion systems, is employed to investigate the potential application of Fe-SA-NSFC. As the result, the FeSA-NSFC achieves high half-wave potentials $\left(E_{1 / 2}\right)$ of 0.91 and $0.82 \mathrm{~V}$ (vs. reversible hydrogen electrode (RHE)) towards the ORR in alkaline and acid electrolyte solutions, respectively, which outperforms those values for the most state-of-the-art noble metal-free electrocatalysts. Furthermore, as an air electrode, the
Fe-SA-NSFC shows a good performance in a zinc (Zn)-air battery, including a large peak power density of $247.7 \mathrm{~mW} \mathrm{~cm}^{-2}$ and a long-term stability over a period of $240 \mathrm{~h}$. Besides, the Co-SA-NSFC shows excellent activity toward hydrogen evolution reaction (HER) in acidic electrolyte solution, which is the most sustainable pathway for hydrogen production.

\section{Results}

Catalyst synthesis. Fe-SA-NSFC was synthesized as an example to describe the multilayer stabilization used to fabricate a M-SAC, as illustrated in Fig. 1a (see details in 'Methods' and Supplementary Fig. 1). In a typical experiment, ferrocene $(0.2 \mathrm{mmol})$, thiourea $(0.7 \mathrm{mmol})$, and PFTA $(0.07 \mathrm{mmol})$ were dissolved in $2 \mathrm{~mL}$ of ethanol. Then, water $(10 \mathrm{ml})$ was added to induce the self-assembly of PFTA towards lamella-type bilayers with hydrophilic surfaces and hydrophobic interlayers ${ }^{34}$. The PFTA bilayers had a sheet-like morphology with sizes up to $4 \mu \mathrm{m}^{34,35}$. The ferrocene was simultaneously confined into the interlayers of the PFTA to achieve PFTA/ferrocene/PFTA layers due to its high hydrophobicity. To further stabilize the ferrocene in the PFTA/ ferrocene/PFTA bilayers, the PFTA surfaces were coated with Ppy layers by adding pyrrole $(124 \mu \mathrm{L})$, which was adsorbed due to hydrogen bonding ${ }^{35}$. Oxidative polymerization of the pyrrole with ammonium persulfate (APS) gave rise to the formation of sheet-like Ppy(PFTA/ferrocenes/PFTA) (Supplementary Fig. 2). Subsequently, the Ppy(PFTA/ferrocene/PFTA) was hydrothermally treated at $150^{\circ} \mathrm{C}$ for $8 \mathrm{~h}$, establishing a free-standing hydrogel through cross-linking of adjacent Ppy layers (Supplementary Fig. 1d $)^{34}$. The obtained hydrogel was freeze-dried and then pyrolysed at $1000{ }^{\circ} \mathrm{C}$ for $1 \mathrm{~h}$ under an Ar atmosphere for carbonization. After cooling to room temperature, Fe-SA-NSFC was produced as a black powder without any further treatments (Supplementary Fig. 1e).

Catalyst characterization. Visualization by bright-field and medium-angle annular dark-field scanning transmission electron microscopy (STEM) and scanning electron microscopy (SEM) indicated the sheet-like morphology of the Fe-SA-NSFC, which was inherited from the PFTA bilayers (Fig. 1b and Supplementary Fig. 2). The powder X-ray diffraction (XRD) pattern of the FeSA-NSFC showed only one peak at $\sim 25^{\circ}$ corresponding to the (002) plane of graphite (Supplementary Fig. 3a) and its Raman spectrum exhibited $D$ and $G$ bands at 1342 and $1585 \mathrm{~cm}^{-1}$ (Supplementary Fig. 4), respectively, indicating the formation of graphitized carbon ${ }^{27}$. High-resolution transmission electron microscopy (HRTEM) images together with XRD verified the absence of crystalline Fe-based nanoparticles or clusters in the $\mathrm{Fe}$ SA-NSFC (Fig. 1c and Supplementary Fig. 3a). The corresponding element mapping images revealed a homogeneous distribution of $\mathrm{C}, \mathrm{N}, \mathrm{S}, \mathrm{F}$, and Fe in the Fe-SA-NSFC (Fig. 1d, e). Furthermore, aberration-corrected high-angle annular dark-field STEM (AC-HAADF-STEM) images showed that numerous separated Fe atoms with an average diameter of $\sim 0.17 \mathrm{~nm}$ were uniformly distributed over all of the graphitized carbon supports (Fig. 1f, g and Supplementary Fig. 5). No larger particles or crystalline Fe phases were observed, validating that the identified $\mathrm{Fe}$ atoms were present as single atoms. The Fe loading in the $\mathrm{Fe}$ SA-NSFC reached $15.3 \mathrm{wt} \%$ when $0.2 \mathrm{mmol}$ of ferrocene was used, as determined by inductively coupled plasma mass spectrometry (ICP-MS) analysis. This loading is higher than that of the most of reported Fe-SACs (Supplementary Table 1) ) $^{3,8,19}$. A continued increase in the amount of ferrocene (e.g., $0.25 \mathrm{mmol}$ ) resulted in the generation of $\mathrm{Fe}$-containing nanoparticles (NPs) and clusters loaded on the N, S, F-co-doped graphitized carbon (Fe-NSFC), as evidenced by XRD and TEM analyses 


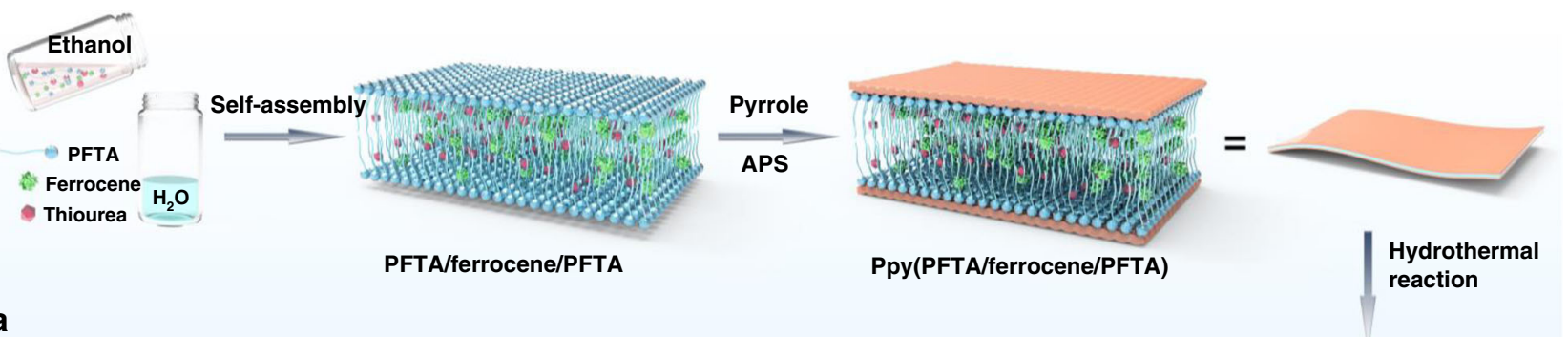

a

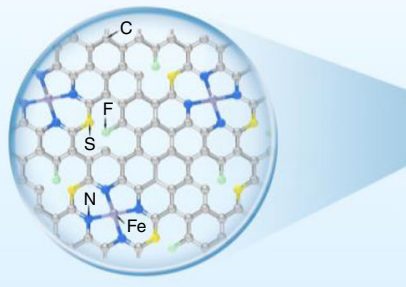

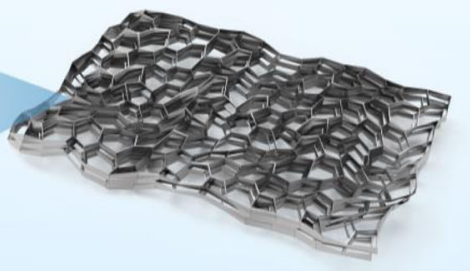

Fe-SA-NSFC

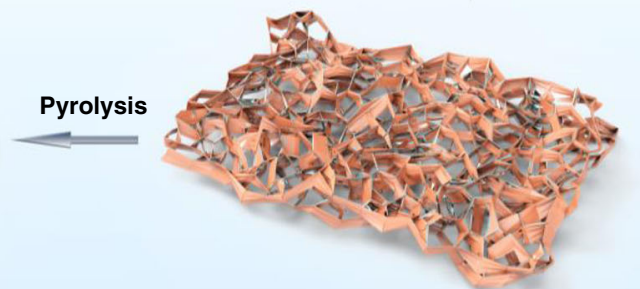

Ppy(PFTA/ferrocene/PFTA) hydrogel
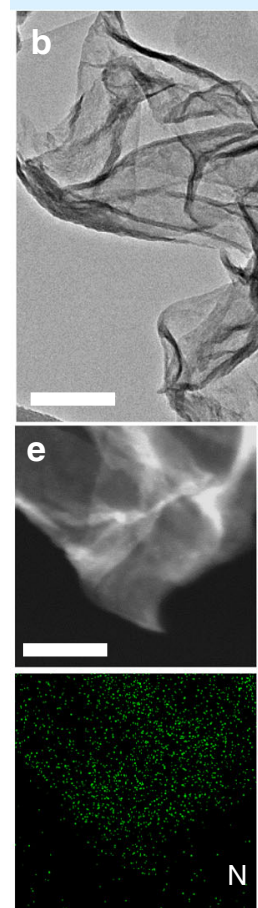

C

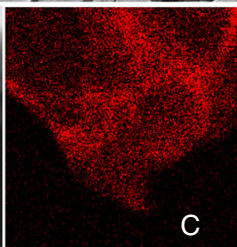

N

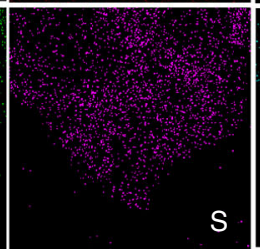

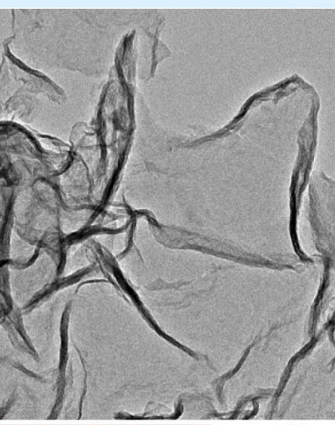
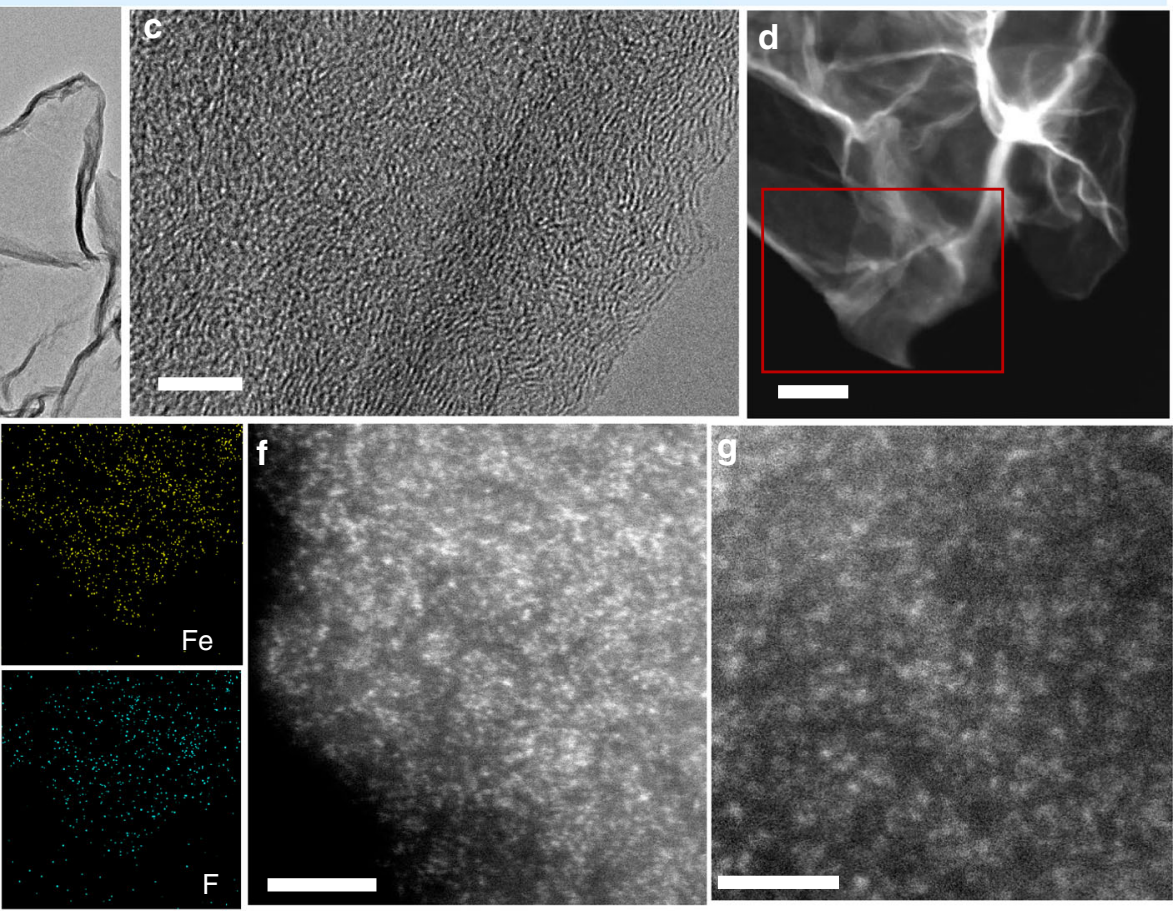

Fig. 1 Synthesis and structural characterization results. a lllustration of the preparation process for the Fe-SA-NSFC and $\mathbf{b}$ TEM, $\mathbf{c} H R T E M$, and $\mathbf{d}$ HAADFSTEM images of the Fe-SA-NSFC. e Enlarged HAADF-STEM image and corresponding element maps for C, Fe, N, S, and F. f AC-HAADF-STEM image and $\mathbf{g}$ high-magnification AC-HAADF-STEM image of the Fe-SA-NSFC. Scale bars: b $200 \mathrm{~nm}, \mathbf{c} 5 \mathrm{~nm}$, d $200 \mathrm{~nm}$, e $100 \mathrm{~nm}$, f $5 \mathrm{~nm}$, and $\mathbf{g} 2 \mathrm{~nm}$.

(Supplementary Figs. 3a and 6). In addition, control experiments (i) in the absence of PFTA and (ii) by using water-soluble Fe precursors instead of ferrocene (e.g., ferrous sulfate heptahydrate, $\mathrm{FeSO}_{4} \cdot 7 \mathrm{H}_{2} \mathrm{O}$ ) failed to achieve the atomic dispersion of $\mathrm{Fe}$ at high loadings pyrolysis (Supplementary Fig. 7). This indicated, again, the excellent ability of the current multilayer confinement to suppress the formation of Fe-containing NPs or clusters during high-temperature pyrolysis.

The synchrotron radiation-based X-ray absorption fine spectroscopy (XAFS) results revealed the atomic structure and coordination state of the Fe species. The X-ray absorption nearedge structure (XANES) spectrum of the Fe-SA-NSFC showed that the $\mathrm{Fe} K$-pre-edge was close to that for $\mathrm{Fe}(\mathrm{II})$ in $\mathrm{FeO}$ but far from that for $\mathrm{Fe}(\mathrm{III})$ in $\mathrm{Fe}_{2} \mathrm{O}_{3}$, indicating that the oxidation state of the $\mathrm{Fe}$ in the Fe-SA-NSFC was +2 (Fig. 2a). The Fourier transform of the $k^{3}$-weighted extended X-ray absorption fine structure (EXAFS) spectrum of the Fe-SA-NSFC displayed a clear peak at ca. $1.57 \AA$ (Fig. 2b), which was ascribed to the Fe-N first coordination shell ${ }^{36}$. Compared with the peaks from $\mathrm{Fe}$ foil, $\mathrm{FeO}$, $\mathrm{Fe}_{2} \mathrm{O}_{3}$, and $\mathrm{FeS}_{2}$ as reference materials, no $\mathrm{Fe}-\mathrm{Fe}$ (ca. $2.20 \AA$ ), Fe-O (ca. $1.45 \AA$ ), and Fe-S (ca. $1.80 \AA$ ) coordination peaks were detected, in accordance with the atomic dispersion of the $\mathrm{Fe}^{37}$. Based on R-space fitting of the EXAFS data, the coordination number of the Fe-N first shell was given by $\mathrm{CN}_{\mathrm{Fe}-\mathrm{N}}=4.4 \pm 0.5$ (Supplementary Fig. 8 and Supplementary Table 2), suggesting that the dominant $\mathrm{Fe}-\mathrm{N}$ structure was $\mathrm{FeN}_{4}$.

$\mathrm{X}$-ray photoelectron spectroscopy (XPS) analysis revealed the binding states of different elements in the Fe-SA-NSFC, as summarized in Supplementary Tables 3-5. The contents of N, S, and $\mathrm{F}$ were $17.2 \%, 2.5 \%$, and 2.2 at\%, respectively (Supplementary Table 3), indicating high doping densities of these heteroatoms. The high-resolution C $1 s$ spectrum from the Fe-SA-NSFC showed four peaks at $284.7,285.8,288.6$, and $291.0 \mathrm{eV}$, which could be assigned the $\mathrm{C}=\mathrm{C}, \mathrm{C}-\mathrm{N}(\mathrm{C}-\mathrm{S}), \mathrm{O}=\mathrm{C}-\mathrm{O}$, and $\mathrm{C}-\mathrm{F}$ bonds, 

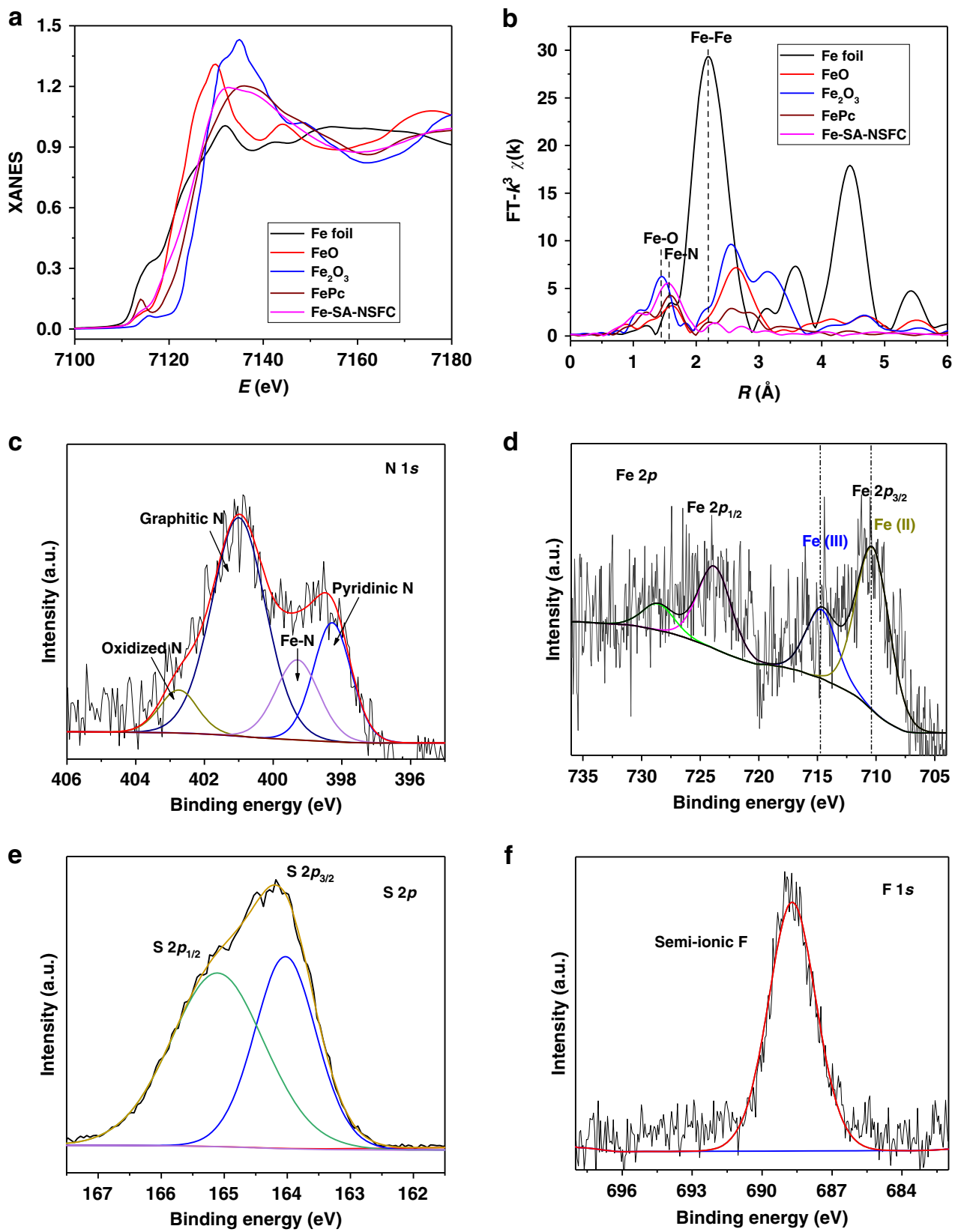

Fig. 2 Atomic structure analysis. a Fe K-edge XANES spectra and $\mathbf{b}$ FT of $k^{3}$-weighted $\chi(k)$-function of EXAFS spectra of Fe-SA-NSFC, where an Fe foil, $\mathrm{FeO}, \mathrm{Fe}_{2} \mathrm{O}_{3}$, and $\mathrm{FePc}$ were used as reference materials. High-resolution X-ray photoelectron spectroscopy (XPS) spectra of $\mathbf{c} \mathrm{N} 1 \mathrm{~s}$, d Fe $2 p$, e $\mathrm{S} 2 p$, and $\mathbf{f} F$ is.

respectively (Supplementary Fig. 9). The N $1 s$ spectrum revealed the presence of four types of $\mathrm{N}$ species, namely, pyridinic $\mathrm{N}$ $(398.6 \mathrm{eV}), \mathrm{Fe}-\mathrm{N}(399.5 \mathrm{eV})$, graphitic $\mathrm{N}(401.2 \mathrm{eV})$, and oxidized $\mathrm{N}(402.5 \mathrm{eV})$ (Fig. 2c) ${ }^{18}$. The high content of $\mathrm{FeN}_{4}(15.0 \%)$ was attributed to the pronounced $\mathrm{N}$-coordination sites that anchored $\mathrm{Fe}$ and enabled the formation of $\mathrm{FeN}_{4}$ moieties with a high density. The high-resolution $\mathrm{Fe} 2 p$ XPS spectrum again confirmed the absence of metallic Fe in the Fe-SA-NSFC, and that $\mathrm{Fe}$ (II) was the dominant Fe (Fig. $2 \mathrm{~d})^{12}$. The S $2 p$ and F $1 s$ XPS spectra revealed the existence of $\mathrm{C}-\mathrm{S}-\mathrm{C}$ covalent bands and semiionic C-F bonds in the Fe-SA-NSFC (Fig. 2e, f) ${ }^{38,39}$.

$\mathrm{N}_{2}$ adsorption-desorption analysis was applied to quantify the porous properties of the Fe-SA-NSFC, in which an increased adsorption volume at a low pressure $\left(P / P_{0}<0.03\right)$ and a distinct hysteresis loop at a high pressure of $P / P_{0}>0.4$ indicated the coexistence of micropores, mesopores, and macropores
(Supplementary Fig 10a). The Brunauer-Emmett-Teller specific surface area and total pore volume of the Fe-SA-NSFC were $\sim 900 \mathrm{~m}^{2} \mathrm{~g}^{-1}$ and $\sim 1.2 \mathrm{~cm}^{3} \mathrm{~g}^{-1}$, respectively, which were much larger than those of the Fe-SA-NSFC before the pyrolysis process $\left(\sim 450 \mathrm{~m}^{2} \mathrm{~g}^{-1}\right.$ and $0.4 \mathrm{~cm}^{3} \mathrm{~g}^{-1}$, respectively). A considerable increase in apparent micropores resulted from the carbonization of ferrocene and PFTA at high temperatures. This may be ascribed to the improved porosity of the Fe-SA-NSF, which is consistent with the pore size distribution analysed by a nonlocal density functional theory (DFT) method (Supplementary Fig. 10b).

Fabrication of M-SA-NSFCs with other metals. The broad scope of this multilayer stabilization strategy was next examined for the preparation of a series of M-SA-NSFCs with different metals, including $\mathrm{Co}, \mathrm{Ru}$, Ir, and $\mathrm{Pt}$, by using the corresponding OMs 
with an optimal dosage. For noble metals, thermal reduction was performed under a $\mathrm{H}_{2} / \mathrm{Ar}$ atmosphere at $250^{\circ} \mathrm{C}$ for $2 \mathrm{~h}$ owing to the high reduction ability of $\mathrm{H}_{2}{ }^{29}$. Similar to the characterization of the Fe-SA-NSFC, the XRD, TEM, HRTEM, elemental mapping, and XPS methods were employed to investigate the crystalline structure, morphology, and element distribution of the obtained M-SA-NSFCs (Supplementary Fig. 3c, d and Supplementary Figs. 11-13). The XPS results revealed the heteroatomdoping structure in noble metal containing catalysts particularly $\mathrm{O}, \mathrm{N}$, and $\mathrm{S}$. This structure was different from Fe-SA-NSFC due to the lower annealing temperature (Supplementary Fig. 13). The AC-HAADF-STEM images revealed the atomic dispersion of the metal atoms on the graphitized carbon for the M-SA-NSFCs $(\mathrm{M}=\mathrm{Co}, \mathrm{Ru}, \mathrm{Ir}$, and Pt) (Fig. 3). The EXAFS analyses indicated no metal-metal coordination (Fig. 3). Moreover, the EXAFS results confirmed that all metal atoms were coordinated with $\mathrm{N}$ (Supplementary Fig. 14). The first-shell coordination numbers of $\mathrm{M}-\mathrm{N}$ were $4.8 \pm 1.6$ for $\mathrm{Co}, 5.0 \pm 0.6$ for $\mathrm{Ru}, 4.0 \pm 0.8$ for $\mathrm{Ir}$, and $4.0 \pm 0.6$ for Pt (Supplementary Table 2), corresponding to $\mathrm{CoN}_{5}$, $\mathrm{RuN}_{5}, \mathrm{IrN}_{4}$, and $\mathrm{PtN}_{4}$, respectively ${ }^{29,40}$. The metal loading of the M-SA-NSFCs could, again, be controlled by adjusting the relative amounts of metal precursors, yielding M-SA-NSFCs with maximum metal loadings of $12.2,10.9,15.7$, and $15.6 \mathrm{wt} \%$ for $\mathrm{Co}, \mathrm{Ru}$, $\mathrm{Ir}$, and $\mathrm{Pt}$, respectively. Again, these values are much higher than those reported in most of the previous publications (Supplementary Table 1$)^{3,10,29,40}$.

Electrocatalytic ORR performance of Fe-SA-NSFC. The electrochemical performance of Fe-SA-NSFC for the ORR and the effect of the $\mathrm{S}$ and $\mathrm{F}$ dopants were studied using rotating disk electrode (RDE) and rotating ring-disk electrode (RRDE) measurements. The prepared SA-Fe supported by N-doped and N,Sdoped graphitized carbons (Fe-SA-NC and Fe-SA-NSC, respectively), as well as that for the commercial $\mathrm{Pt} / \mathrm{C}$ were evaluated for comparison (Supplementary Figs. 15 and 16). Cyclic voltammetry (CV) curves of all the Fe-SACs displayed a clear cathodic ORR peak in an $\mathrm{O}_{2}$-saturated $0.1 \mathrm{M} \mathrm{KOH}$ electrolyte solution (Supplementary Fig. 17a). The onset potential was defined as the potential required for generating an ORR current density of $0.1 \mathrm{~mA} \mathrm{~cm}^{-2}$ in linear sweep voltammetry (LSV) curves ${ }^{41}$. The Fe-SA-NSFC demonstrated the highest ORR activity herein in terms of the most positive onset potential of $1.01 \mathrm{~V}$ vs. RHE (Fig. 4a). The $E_{1 / 2}$ was up to $0.91 \mathrm{~V}$, which surpassed the values for the Fe-SA-NC $(0.86 \mathrm{~V})$, Fe-SA-NSC $(0.88 \mathrm{~V})$, and $\mathrm{Pt} / \mathrm{C}$ $(0.85 \mathrm{~V})$ (Supplementary Table 6). The Fe-SA-NSFC also presented a comparable ORR activity with most of the reported state-of-the-art Pt-free catalysts, such as the atomic $\mathrm{Fe}-\mathrm{N}_{x}$ moieties anchored on carbon support (Fe-NC SACs) $(0.90 \mathrm{~V})^{36}, \mathrm{Fe}-$ isolated single atoms on $\mathrm{S}$ - and $\mathrm{N}$-co-doped carbon (Fe-ISA/ SNC) $(0.896 \mathrm{~V})^{37}$, and $\mathrm{N}$, phosphorus (P), and S co-doped hollow carbon polyhedron (Fe-SAs/NPS-HC) $(0.912 \mathrm{~V})^{42}$ (Supplementary Table 7). Moreover, the Fe-SA-NSFC exhibited the highest kinetic current density $\left(J_{\mathrm{k}}\right)$ at $0.85 \mathrm{~V}$ herein of $61.5 \mathrm{~mA} \mathrm{~cm}^{-2}$ compared to that for the Fe-SA-NC $\left(5.3 \mathrm{~mA} \mathrm{~cm}^{-2}\right)$, Fe-SA-NSC $\left(13.6 \mathrm{~mA} \mathrm{~cm}^{-2}\right)$, and $\mathrm{Pt} / \mathrm{C}$ catalyst $\left(5.2 \mathrm{~mA} \mathrm{~cm}^{-2}\right)$. The Tafel slope of the Fe-SA-NSFC was measured to be $53 \mathrm{mV} \mathrm{dec}^{-1}$, which was lower than the values of $70 \mathrm{mV} \mathrm{dec}^{-1}$ for the Fe-SA$\mathrm{NC}, 69 \mathrm{mV} \mathrm{dec}^{-1}$ for the Fe-SA-NSC, and $72 \mathrm{mV} \mathrm{dec}^{-1}$ for the $\mathrm{Pt} / \mathrm{C}$ (Fig. 4b). Accordingly, $\mathrm{S}$ and $\mathrm{F}$ co-doping greatly accelerated the ORR kinetics for the $\mathrm{FeN}_{4}$ active sites in alkaline solution.

To further probe the ORR kinetics of the Fe-SA-NSFC, RDE measurements at different speeds of rotation were performed, and the related Koutecký-Levich (K-L) plots were acquired. Linear and almost parallel K-L plots were achieved at different applied potentials (Supplementary Fig. 17b, c), reflecting first-order reaction kinetics towards the concentration of dissolved oxygen and a similar electron-transfer number $(n)$. The electron-transfer number was calculated to be 3.98 at $0.4 \mathrm{~V}$, pointing towards a four-electron $\left(4 e^{-}\right)$oxygen reduction process $^{27}$. An RRDE technique was employed to monitor the generation of $\mathrm{H}_{2} \mathrm{O}_{2}$ during the ORR process with the ring potential of $1.45 \mathrm{~V}$ vs. RHE. The $\mathrm{H}_{2} \mathrm{O}_{2}$ yield from the $\mathrm{Fe}-\mathrm{SA}$-NSFC was below $2 \%$ in the potential range from 0.40 to $0.90 \mathrm{~V}$, implying an excellent selectivity of the oxygen reduction towards $\mathrm{H}_{2} \mathrm{O}$ formation (Fig. 4c).

To evaluate the durability of the Fe-SA-NSFC, accelerated durability tests (ADTs) and $i-t$ chronoamperometry techniques were used. After 25,000 potential cycles, the $E_{1 / 2}$ of the Fe-SANSFC decreased by only $2 \mathrm{mV}$ (Fig. 4d), which was much smaller than that of $\mathrm{Pt} / \mathrm{C}(50 \mathrm{mV})$ (Supplementary Fig. 17d). A durability test at a constant potential of $0.9 \mathrm{~V}$ for $25,000 \mathrm{~s}$ at a rotation speed of 1600 r.p.m. showed that only $4.4 \%$ of the current density was lost for the Fe-SA-NSFC (Fig. 4d, inset), again confirming the good ORR stability of the Fe-SA-NSFC.

The ORR performance of the Fe-SA-NSFC in a $0.1 \mathrm{M} \mathrm{HClO}_{4}$ acid electrolyte solution reflected a significantly improved ORR activity in terms of a high $E_{1 / 2}$ of $0.82 \mathrm{~V}$ compared with those of the Fe-SA-NC $\left(E_{1 / 2}=0.72 \mathrm{~V}\right)$ and Fe-SA-NSC $\left(E_{1 / 2}=0.79 \mathrm{~V}\right)$, and it was only $40 \mathrm{mV}$ lower than that of the $\mathrm{Pt} / \mathrm{C}$ catalyst $\left(E_{1 / 2}=0.86 \mathrm{~V}\right)$ (Fig. 4e and Supplementary Table 6). The $J_{\mathrm{k}}$ of FeSA-NSFC was as high as $1.25 \mathrm{~mA} \mathrm{~cm}^{-2}$ at $0.85 \mathrm{~V}$, which was 4.0 and 3.0 times higher than those of the Fe-SA-NC $\left(J_{k}=0.31 \mathrm{~mA}\right.$ $\left.\mathrm{cm}^{-2}\right)$ and Fe-SA-NSC $\left(J_{\mathrm{k}}=0.41 \mathrm{~mA} \mathrm{~cm}^{-2}\right)$. The ORR activity of the Fe-SA-NSFC was superior or comparable to those of most reported non-noble metal electrocatalysts, such as N-coordinated SA Mn sites on graphitic carbon $(\mathrm{Mn}-\mathrm{N}-\mathrm{C})\left(E_{1 / 2}=0.80 \mathrm{~V}\right)^{31}, \mathrm{Fe}-$ SAs/NPS-HC $\left(E_{1 / 2}=0.80 \mathrm{~V}\right)^{42}$, Fe-N-C catalysts prepared by ball-milling-assisted method $\left(E_{1 / 2}=0.81 \mathrm{~V}\right)^{43,44}$, and SA-Fe-N catalyst $\left(E_{1 / 2}=0.812 \mathrm{~V}\right)^{42}$ (Supplementary Tables 6 and 8 ). However, Fe-SA-NSFC exhibits a lower activity than some catalysts with much lower Fe loading such as Fe-doped ZIFderived catalysts $\left(E_{1 / 2}=0.85 \mathrm{~V} \text {, Fe loading: } 0.45 \text { at } \%\right)^{27}$ and ammonia-activated Fe-N-C (outperformed commercial $\mathrm{Pt} / \mathrm{C}$ ) ${ }^{45}$. Some $\mathrm{Fe}$ atoms that were trapped in the carbon layer probably could not contribute to ORR activity due to their inaccessibility. Therefore, the next challenge is proposed to enhance the accessibility of the single $\mathrm{Fe}$ atoms, while keeping the high loading.

In addition, the Tafel slope of the Fe-SA-NSFC was determined to be $57 \mathrm{mV} \mathrm{dec}^{-1}$, indicating that the Fe-SA-NSFC has the similar rate-determining step (RDS) of the ORR in the acidic electrolyte solutions (Supplementary Fig. 18a). The fast ORR kinetics of the Fe-SA-NSFC could favour $\mathrm{H}_{2} \mathrm{O}$ formation through the $4 e^{-}$pathway $\left(n=3.97\right.$ and $\mathrm{H}_{2} \mathrm{O}_{2}$ yield $<1.7 \%$ ) (Fig. $4 \mathrm{f}$ ). In addition, the ADT result demonstrated that the $E_{1 / 2}$ of Fe-SANSFC only decreased by $24 \mathrm{mV}$ after $20,000 \mathrm{CV}$ scans, again revealing a durability superior to that of commercial $\mathrm{Pt} / \mathrm{C}$ ( $\sim 63 \mathrm{mV}$ loss) (Supplementary Fig. 18d, e). Turnover frequencies (TOFs), representing the intrinsic activity of a catalyst, can be calculated as the total number of electron transfers per second during ORR over the number of ORR active sites (for details see the Supplementary Information $)^{46}$. The TOFs of Fe-SA-NSFC were 0.22 at $0.85 \mathrm{~V}$ in alkaline solution and $0.17 \mathrm{e} \mathrm{s}^{-1}$ site $^{-1}$ at $0.8 \mathrm{~V}$ in acid solutions, which were in the range of similar activities reported in previous works, indicating again, that $\mathrm{Fe}$ SA-NSFC is a promising catalyst material for ORR applications (Supplementary Table 9) ${ }^{46,47}$.

Correlation of ORR activity with S, F-co-doped FeN4 active sites. To understand why additional doping of $S$ and $F$ could 


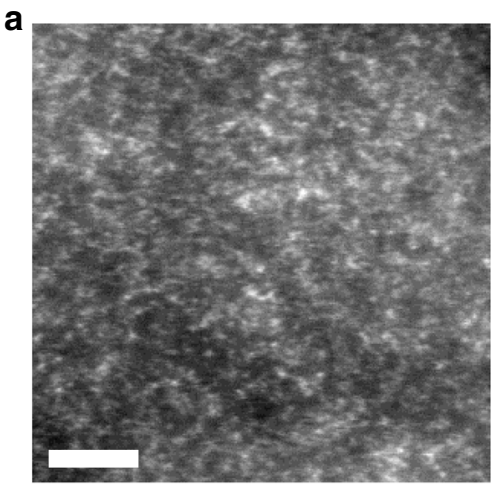

b
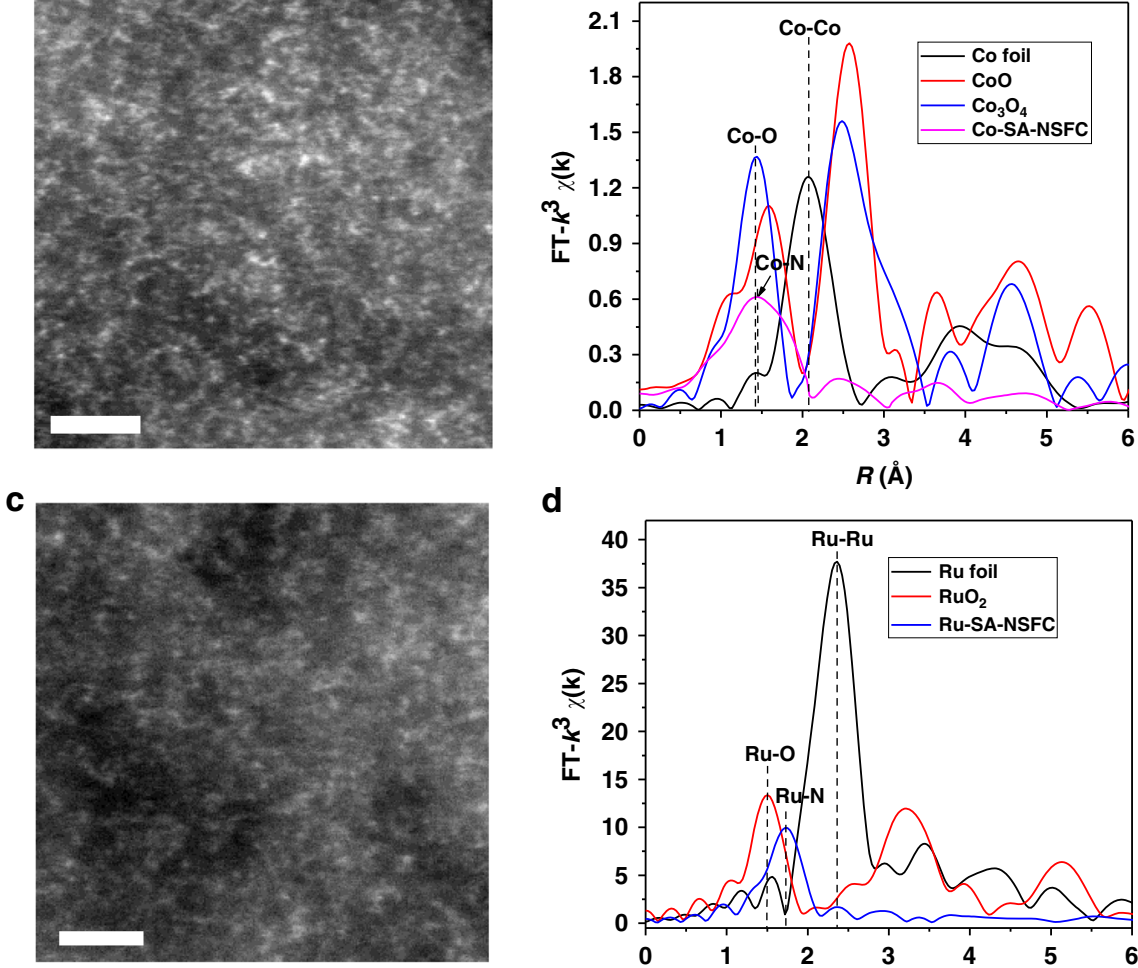

d
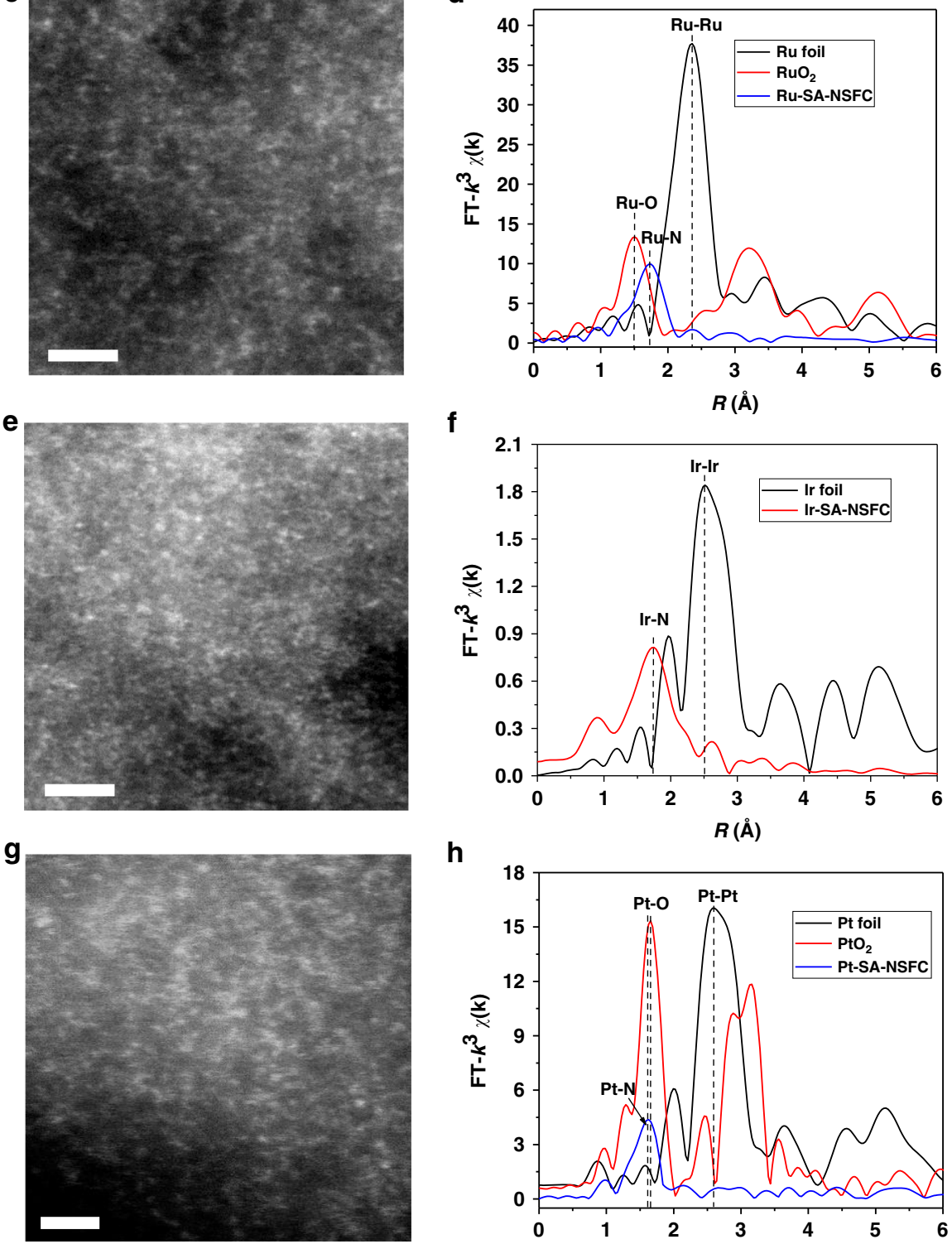

h

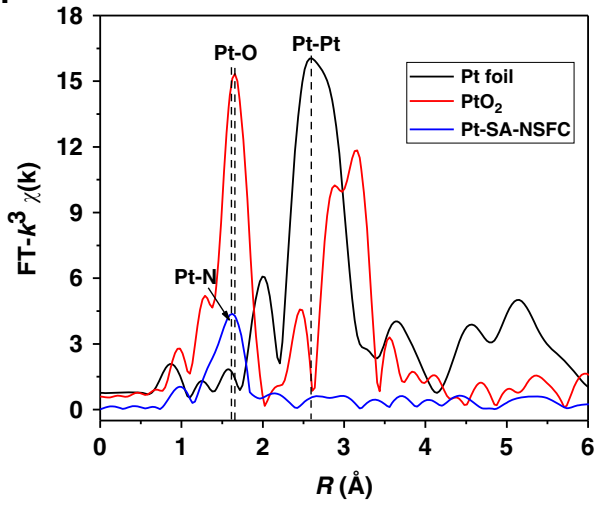

Fig. 3 Characterization of M-SA-NSFCs with other metals. $\mathbf{a}, \mathbf{c}, \mathbf{e}, \mathbf{g}$ AC-HAADF-STEM images and $\mathbf{b}, \mathbf{d}, \mathbf{f}, \mathbf{h}$ EXAFS experimental data: $\mathbf{a}, \mathbf{b}$ Co-SA-NSFC; c, d Ru-SA-NSFC; e, f Ir-SA-NSFC; and $\mathbf{g}$, h Pt-SA-NSFC. Scale bar: $2 \mathrm{~nm}$. 
a
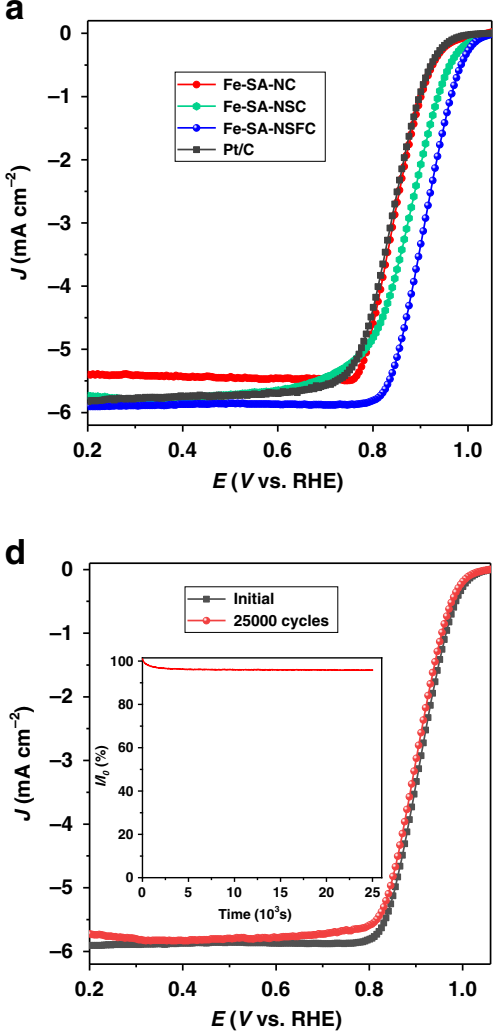

g

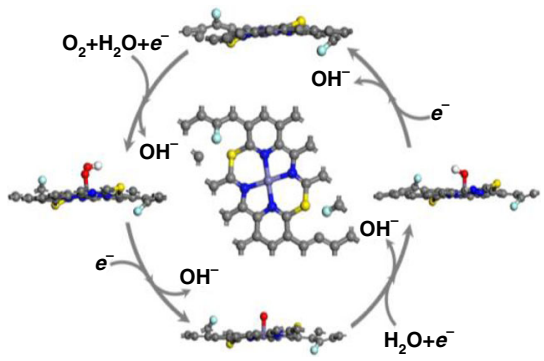

b

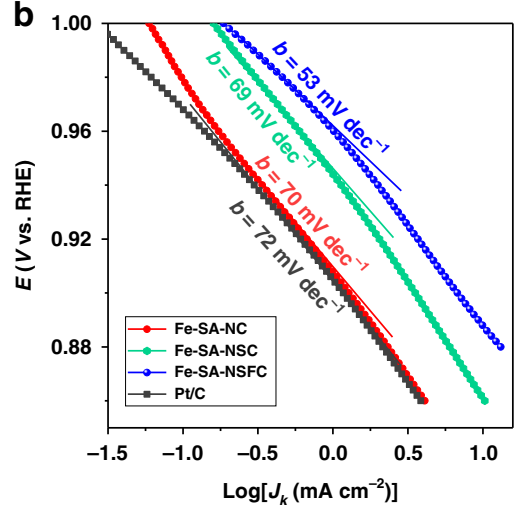

e

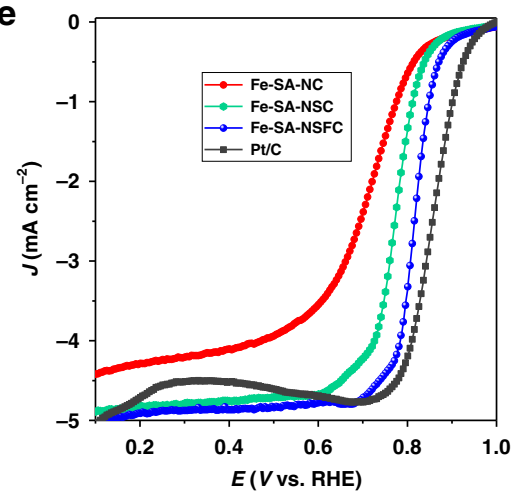

h

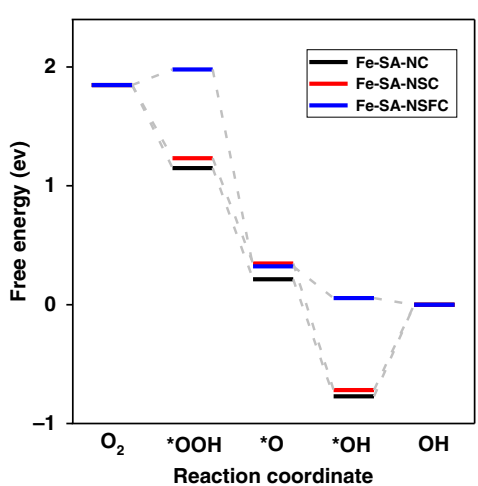

c

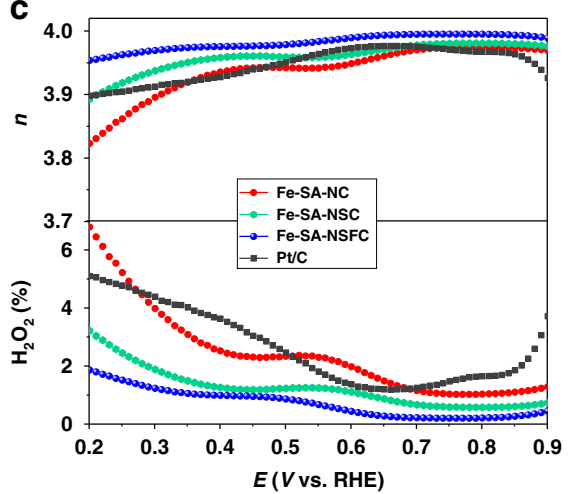

f

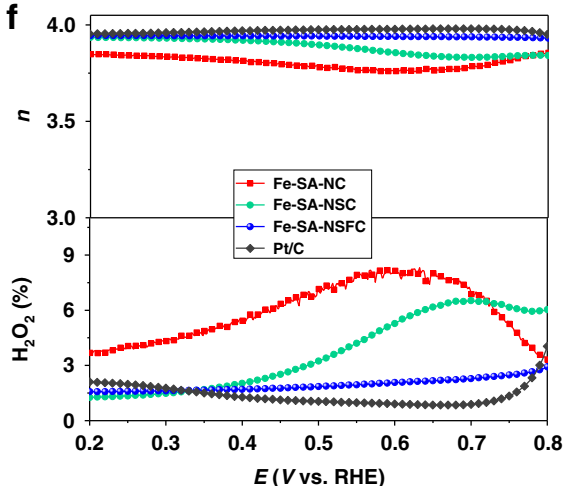

i

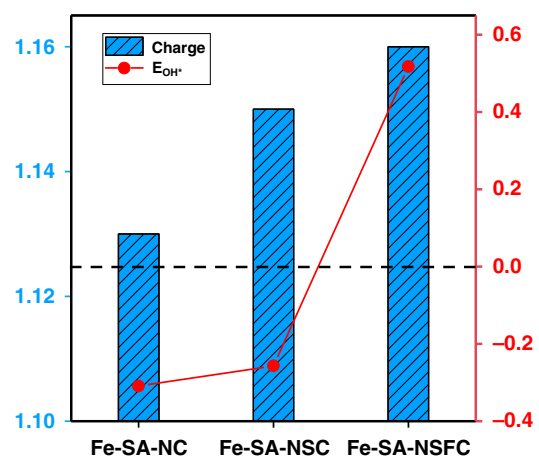

Fig. 4 Electrocatalytic ORR performance. a ORR polarization curves, b Tafel plots, and c electron-transfer number ( $n$ ) (top) and $\mathrm{H}_{2} \mathrm{O}_{2}$ yield (bottom) for the Fe-SA-NC, Fe-SA-NSC, Fe-SA-NSFC, and Pt/C in $0.1 \mathrm{M} \mathrm{KOH}$ solution. d ORR polarization curves of the Fe-SA-NSFC before and after $25000 \mathrm{CV}$ cycles; the inset of $\mathbf{d}$ shows the $i-t$ curve at $0.9 \mathrm{~V}$ and 1600 r.p.m. for 25,000 s. e ORR polarization curves and $\mathbf{f}$ electron-transfer number ( $n$ ) (top) and $\mathrm{H}_{2} \mathrm{O}_{2}$ yield (bottom) for the Fe-SA-NC, Fe-SA-NSC, Fe-SA-NSFC, and Pt/C in $0.1 \mathrm{M} \mathrm{HClO}_{4}$ solution with rotation speed of 900 r.p.m. $\mathbf{g}$ Proposed $4 e^{-}$reduction mechanism in alkaline solution for the ORR on Fe-SA-NSFC; the inset shows the structure of the Fe-SA-NSFC. $\mathbf{h}$ Free energy diagram for the Fe-SA-NC, Fe$\mathrm{SA}-\mathrm{NSC}$, and Fe-SA-NSFC ( $U=0 \mathrm{~V}$ vs. RHE, $\mathrm{pH} 13)$. $\mathbf{i} \mathrm{OH}^{\star}$ binding energies and Mulliken charges of the FeN $\mathrm{F}_{4}$ active centres in the Fe-SA-NC, Fe-SA-NSC, and Fe-SA-NSFC.

enhance the ORR activity of $\mathrm{FeN}_{4}$ sites, the Gibbs free energy changes of the $4 \mathrm{e}$ - ORR process were computed for the three structures of Fe-SA-NSFC, Fe-SA-NC and Fe-SA-NSC (Fig. 4g), which were constructed according to the XANES and XPS results, literature ${ }^{46}$, and geometrically optimized by a density functionalbased tight binding method (http://www.dftb.org) (Supplementary Figs. 19-22, see the details in the Supplementary Information). The free energy diagram for $U=0 \mathrm{~V}$ (vs. RHE) and $\mathrm{pH} 13$ inferred that the $\mathrm{OH}^{*}$ reduction was the $\mathrm{RDS}$ for $\mathrm{FeN}_{4}$ active sites in both the Fe-SA-NC and Fe-SA-NSC with high free energy changes of +0.77 and $+0.72 \mathrm{eV}$, respectively. In contrast, the free energy change for $\mathrm{OH}^{*}$ reduction on the $\mathrm{FeN}_{4}$ active sites with $\mathrm{S}$, F co-doping was significantly decreased to $-0.05 \mathrm{eV}$ (Fig. 4h), suggesting that the ORR process on the Fe-SA-NSFC was thermodynamically favoured compared to that on the Fe-SA-NC and $\mathrm{Fe}-\mathrm{SA}-\mathrm{NSC}^{48}$. Mulliken charge analysis revealed an increased positive charge density for $\mathrm{Fe}$ sites in the $\mathrm{S}, \mathrm{F}$-co-doped $\mathrm{FeN}_{4}$ centre over that for the S-doped $\mathrm{FeN}_{4}$ (Fe-SA-NSC) and $\mathrm{FeN}_{4}$ (Fe-SA-NC) (Fig. 4i and Supplementary Fig. 24). As the positively charged site was more unfavourable for adsorption of ORR intermediates, this result was also consistent with the enhanced ORR activity of the Fe-SA-NSFC ${ }^{49}$. Indeed, the calculated adsorption energy of $\mathrm{OH}^{*}$ on the $\mathrm{FeN}_{4}$ active site was significantly increased from $-0.31 \mathrm{eV}$ for the Fe-SA-NC to $+0.52 \mathrm{eV}$ for the Fe-SA-NSFC (Fig. 4i and Supplementary Table 10). A volcano curve clearly demonstrated a relationship between the ORR activity and the adsorption energy of $\mathrm{OH}^{*}$ (Supplementary Fig. 25), in which Fe-SA-NC appeared on the left side of the peak. 


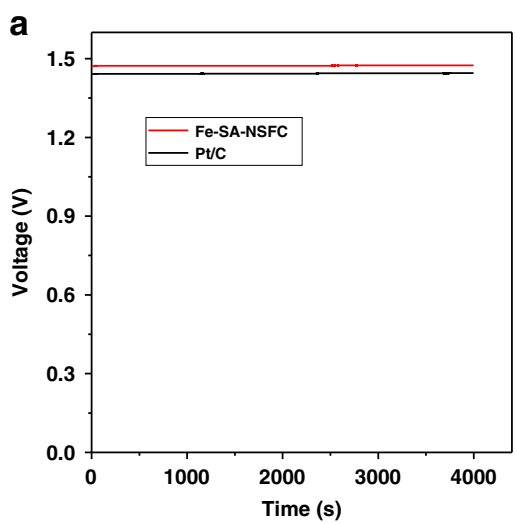

b
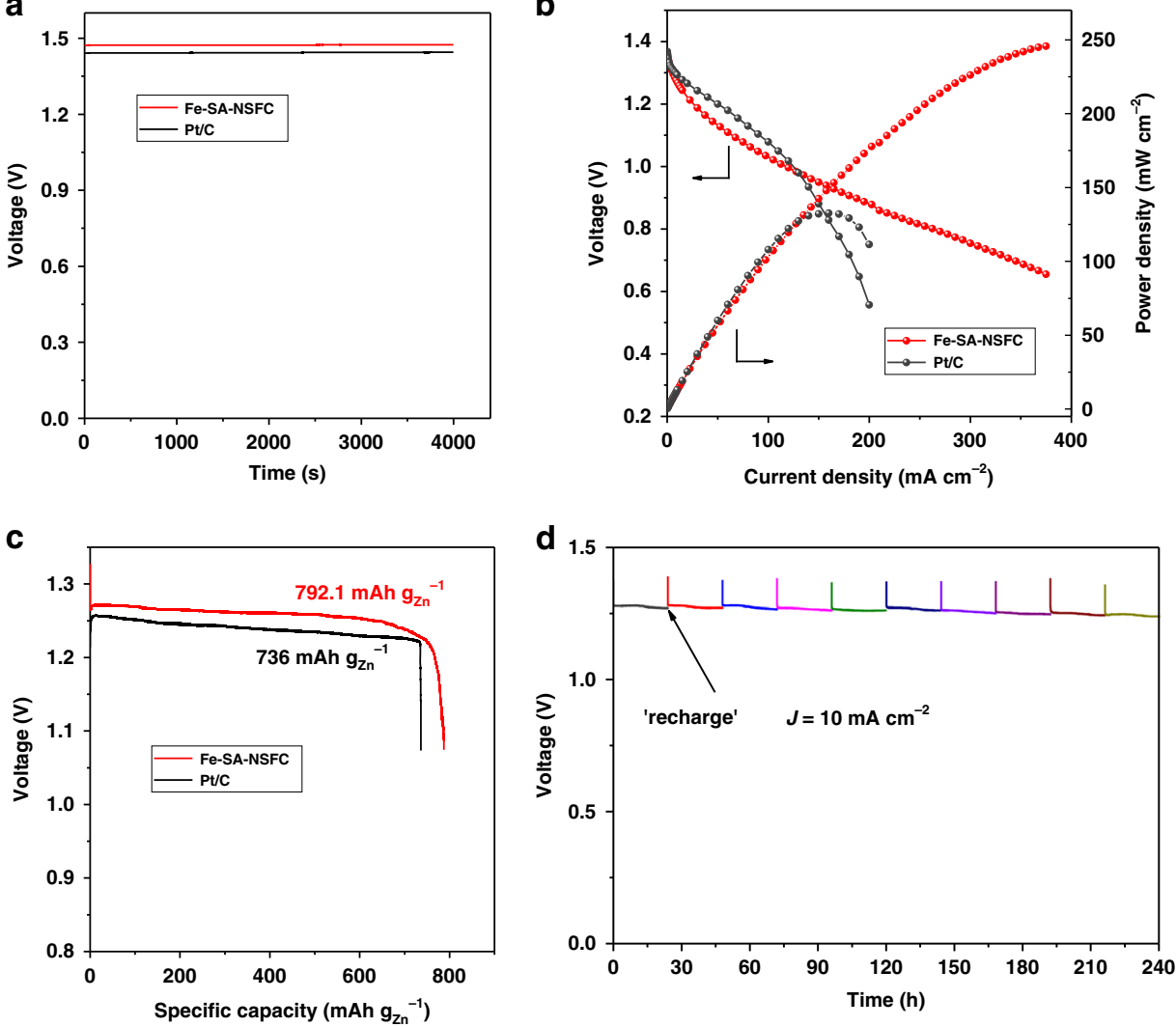

Fig. 5 Performance of the Fe-SA-NSFC and Pt/C catalysts in a Zn-air battery. a The open-circuit voltage curves, b discharge polarization curves and corresponding power density plots, and $\mathbf{c}$ long-term galvanostatic discharge curves. The specific capacity was normalized to the mass of consumed $\mathrm{Zn}$. d "Recharging" the Zn-air battery with Fe-SA-NSFC as the cathode catalyst by replenishing the $\mathrm{Zn}$ anode and electrolyte.

The strong binding between the surface of the $\mathrm{FeN}_{4}$ active sites and oxygen slowed the desorption of $\mathrm{OH}^{*}$, which hindered the completion of the ORR process. With S, F co-doping, the increased positive adsorption energy of $\mathrm{OH}^{*}$ on $\mathrm{FeN}_{4}$ active centres could result in fast desorption of $\mathrm{OH}^{*}$ and regeneration of active sites, achieving an ORR performance for Fe-SA-NSFC that is close to the apex of the volcano ${ }^{50}$.

Zn-air battery performance. For practical application in energy devices, a primary Zn-air battery was assembled utilizing the Fe-SA-NSFC as an air electrode in a $6.0 \mathrm{M}$ $\mathrm{KOH}$ electrolyte containing $0.2 \mathrm{M}$ zinc acetate $\left(\mathrm{Zn}(\mathrm{OAc})_{2}\right)$ (see the details in 'Methods'). The Fe-SA-NSFC-based battery gave rise to a larger open-circuit voltage of $1.47 \mathrm{~V}$ than that of the Pt/C catalyst used as a reference (1.45 V) (Fig. 5a). The maximum power density of the Fe-SA-NSFC was as high as $247.7 \mathrm{~mW} \mathrm{~cm}^{-2}$ (Fig. 5b), which considerably outperformed those of the $\mathrm{Pt} / \mathrm{C}$ catalyst $\left(133 \mathrm{~mW} \mathrm{~cm}^{-2}\right)$ and most state-of-theart noble metal-free catalysts, such as Fe-SAs/NPS-HC

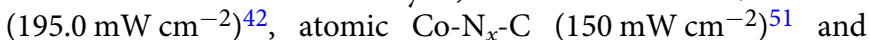
atomically dispersed $\mathrm{Fe}-\mathrm{N}_{4}$ in $\mathrm{N}$-doped porous carbon $\left(\mathrm{Fe}-\mathrm{N}_{4}\right.$ SAs/NPC) $\left(232 \mathrm{~mW} \mathrm{~cm}^{-2}\right)^{52}$ (Supplementary Table 11). Furthermore, the Fe-SA-NSFC-based Zn-air battery delivered a specific capacity of $792.1 \mathrm{mAh} \mathrm{g}_{\mathrm{Zn}}{ }^{-1}$ at $10 \mathrm{~mA} \mathrm{~cm}^{-2}$, corresponding to $\sim 96.6 \%$ utilization of the theoretical capacity $\left(\sim 820 \mathrm{mAh} \mathrm{g}_{\mathrm{Zn}}{ }^{-1}\right)$ (Fig. $\left.5 \mathrm{c}\right)^{18}$. It worked stably in a mechanically rechargeable battery by only refuelling the consumed zinc anode and electrolytes at the end of each discharge. No noticeable degradation was observed after 10 cycles over a period of $240 \mathrm{~h}$ at a current density of $10 \mathrm{~mA} \mathrm{~cm}^{-2}$ (Fig. $5 \mathrm{~d}$ ). When being used as bifunctional oxygen electrocatalyst for a rechargeable $\mathrm{Zn}$-air battery, Fe-SA-NSFC could also stably operate for $120 \mathrm{~h}$ at a constant charge-discharge current density of $10 \mathrm{~mA} \mathrm{~cm}^{-2}$ (Supplementary Fig. 26). The charge voltage was larger than $2.0 \mathrm{~V}$ as a result of the poor oxygen evolution reaction activity of Fe-SANSFC (Supplementary Fig. 27).

Electrocatalytic HER performances of $\mathrm{M}$-SA-NSFC $(\mathrm{M}=\mathrm{Co}$, $\mathbf{R u}, \mathbf{I r}$, and $\mathbf{P t}$ ). The electrochemical HER performances of other $\mathrm{M}$-SA-NSFC $(\mathrm{M}=\mathrm{Co}, \mathrm{Ru}, \mathrm{Ir}$, and $\mathrm{Pt}) \mathrm{SACs}$ were investigated in a $0.5 \mathrm{M} \mathrm{H}_{2} \mathrm{SO}_{4}$ electrolyte solution. The Co-SA-NSFC exhibited an onset potential of $29 \mathrm{mV}$ (Supplementary Fig. 28a). The overpotential was measured to be $104 \mathrm{mV}$ at a current density of $10 \mathrm{~mA} \mathrm{~cm}^{-2}$, which was only $\sim 71 \mathrm{mV}$ lower than that of a benchmark $\mathrm{Pt} / \mathrm{C}$ catalyst $\left(32 \mathrm{mV}\right.$ at $\left.10 \mathrm{~mA} \mathrm{~cm}^{-2}\right)$. Moreover, this value was much lower than those for most previously reported Co-based HER electrocatalysts (Supplementary Table 12), such as $\mathrm{Co}$ and $\mathrm{N}$ co-doped mesoporous graphitic carbon catalysts $\left(286 \mathrm{mV} \text { at } 10 \mathrm{~mA} \mathrm{~cm}{ }^{-2}\right)^{53}$, a carbon supporting molecular $\mathrm{CoN}_{x}$ site catalyst $\left(133 \mathrm{mV} \text { at } 10 \mathrm{~mA} \mathrm{~cm}^{-2}\right)^{54}, \mathrm{Co}_{1}-\mathrm{N}_{4} /$ phosphorized carbon nitride $\left(154 \mathrm{mV} \text { at } 10 \mathrm{~mA} \mathrm{~cm}^{-2}\right)^{55}$, and $\mathrm{N}$ doped carbon nanotube hollow polyhedron supporting $\mathrm{CoP}$ nanoparticles $\left(140 \mathrm{mV} \text { at } 10 \mathrm{~mA} \mathrm{~cm}^{-2}\right)^{56}$. The Tafel plot of CoSA-NSFC provided further insight into the HER pathway. The Tafel slope of Co-SA-NSFC was $\sim 66 \mathrm{mV} \mathrm{dec}^{-1}$ (Supplementary Fig. 28b), suggesting a Volmer-Heyrovsky mechanism for the Co-SA-NSFC catalyst and also indicating that the electrochemical $\mathrm{H}^{*}$ desorption was the RDS ${ }^{54}$. The electrochemical HER performances of Ru-SA-NSFC, Ir-SA-NSFC, and Pt-SA-NSFC were also studied. The overpotentials at a current density of $10 \mathrm{~mA} \mathrm{~cm}^{-2}$ of Ru-SA-NSFC, Ir-SA-NSFC, and Pt-SA-NSFC were 62,67 and $45 \mathrm{mV}$, respectively, implying comparable 
HER activities with reported noble metal-based electrocatalysts (Supplementary Table 12) (57-62. $^{\text {. }}$

\section{Discussion}

The key challenge of M-SACs has been a low metal loading, which has hampered both fundamental and practical applications. We demonstrated a versatile multilayer stabilization approach for fabricating high-loading M-SACs with powerful confinement and stabilization capacity towards metal species. A variety of nonprecious and noble metals achieved atomic dispersion on graphitized carbon supports with a record metal loading of up to nearly $16 \mathrm{wt} \%$. The optimized Fe-SAC, namely, the Fe-SA-NSFC, demonstrated a remarkable ORR performance and outperformed a commercial $\mathrm{Pt} / \mathrm{C}$ catalyst in a Zn-air battery with regard to its long-term stability. Moreover, the optimized Co-SA-NSFC showed a good HER performance in acid media. Our method is very versatile in terms of metal species and the control of their loading. Therefore, it serves as a versatile platform to further explore the potential of high-loading M-SACs and their applications in energy devices and catalysis in other fields, including artificial photosynthesis and synthetic organic chemistry.

\section{Methods}

Preparation of the Fe-SA-NSFCs. Ferrocene $(0.2 \mathrm{mmol})$, thiourea $(0.7 \mathrm{mmol})$, and PFTA $(0.07 \mathrm{mmol})$ were dissolved in ethanol $(2 \mathrm{~mL})$ and then water $(10 \mathrm{~mL})$ was added. After vigorous stirring for $10 \mathrm{~min}$, pyrrole $(124 \mu \mathrm{L})$ was added dropwise into the above solution with stirring for $20 \mathrm{~min}$. The APS aqueous solution $(0.18 \mathrm{M}, 1 \mathrm{~mL})$ was then added and the mixture was stirred for $10 \mathrm{~s}$, and then left without stirring for $4 \mathrm{~h}$ to form a dark hydrogel. This hydrogel was then transferred into a Teflon-lined stainless-steel autoclave and heated at $150^{\circ} \mathrm{C}$ for $8 \mathrm{~h}$. The prepared hydrogel was freeze-dried and pyrolysed at $1000^{\circ} \mathrm{C}$ for $1 \mathrm{~h}$ with a heating rate of $35^{\circ} \mathrm{C} \mathrm{min}-1$ under flowing $\mathrm{Ar}$ (flow rate: $50 \mathrm{~mL} \mathrm{~min}^{-1}$ ). Fe-SA-NSFCs with different Fe loadings and FeNSFCs were fabricated by using $0.1,0.15$, and $0.25 \mathrm{mmol}$ ferrocene, respectively.

Preparation of the Fe-NP-NSC and Fe-NP-NSFC. Fe-NP-NSC was synthesized in the absence of PFTA, and Fe-NP-NSFC was fabricated using $\mathrm{FeSO}_{4} \cdot 7 \mathrm{H}_{2} \mathrm{O}$ $(0.2 \mathrm{mmol})$ as the $\mathrm{Fe}$ precursor. The experimental procedures were the same as for Fe-SA-NSFC.

Preparation of the Fe-SA-NC and Fe-SA-NSC. Fe-SA-NC without S, F dopants and Fe-SA-NSC without F dopants were synthesized using a similar method described above. For the Fe-SA-NSC, the PFTA in the hydrogel formed after the hydrothermal reaction was removed by $1 \mathrm{M} \mathrm{HCl}$ ethanol solution and then rinsed with water three times ${ }^{34}$. Then, the hydrogel was freeze-dried and pyrolysed to obtain Fe-SA-NSC. The Fe-SA-NC was fabricated in the absence of thiourea. The APS and PFTA were washed out after polymerization of the Ppy for $4 \mathrm{~h}$. The following procedures, including hydrothermal reaction and pyrolysis, were the same as mentioned above.

Preparation of the M-SA-NSFCs $(\mathbf{M}=\mathbf{C o}, \mathbf{R u}, \mathbf{I r}$, and $\mathbf{P t})$. These catalysts were synthesized using similar procedures, whereas cobaltocene $(0.15 \mathrm{mmol})$, ruthenocene $(0.15 \mathrm{mmol}),(1,5$-Cyclooctadiene)(methoxy)iridium(I) dimer $(0.06 \mathrm{mmol})$, and platinum(II) acetylacetonate $(0.10 \mathrm{mmol})$ were used as the corresponding metal precursors. Herein, another $0.8 \mathrm{~mL}$ of tetrahydrofuran was added to the ethanol to improve the solubility of the noble metal precursors. The same pyrolysis process as that used for the Fe-SA-NPSFC was used for the preparation of Co-SAC. For the noble metal SACs, the thermal reduction process was carried out at $250^{\circ} \mathrm{C}$ for $2 \mathrm{~h}$ under a $\mathrm{H}_{2} / \mathrm{Ar}$ atmosphere $\left(100 \mathrm{~mL} \mathrm{~min}^{-1}\right.$ for $\mathrm{H}_{2}$ and $50 \mathrm{~mL} \mathrm{~min}^{-1}$ for $\mathrm{Ar}$ ).

Physical characterization. The crystalline phases in the samples were investigated by powder XRD with a Rigaku $\mathrm{D} / \max 2500$ diffractometer $\left(\mathrm{CuKa} \alpha_{1}\right.$ radiation, $\lambda=1.54059 \AA$ A $)$. The metal loadings were tested by ICP-MS on a VISTA MPX (Varian, Inc.). The porous structure was analysed with $\mathrm{N}_{2}$ adsorption-desorption experiments conducted at $77 \mathrm{~K}$ on a Quantachrome SI-MP Instrument. The morphology was characterized by field-emission SEM on a JSM-7800F operating at $15 \mathrm{kV}$ and TEM on a JEOL-2100F. The HRTEM images and element mappings were collected using Tecnai G2 F30 S-Twin TEM (FEI, The Netherlands) operated at $200 \mathrm{kV}$. The HAADF-STEM images were obtained by using a JEOL JEMARM200F S/TEM with a spherical aberration corrector. The XAFS analysis of Fe K-edge, Co K-edge, Ru K-edge, Ir K-edge, and Pt L3-edge, and their corresponding references were obtained at the 1W1B station of the Beijing Synchrotron Radiation Facility that was operated at $2.5 \mathrm{GeV}$ with a maximum current of $250 \mathrm{~mA}$. The acquired EXAFS data were analysed according to the standard procedures using the
ATHENA module implemented in the IFEFFIT software packages (see the details in Supplementary Materials)

Electrochemical ORR measurements. A CHI 760E electrochemical station $(\mathrm{CH}$ Instruments, Inc., Shanghai) was employed to measure the electrochemical performance using a standard three-electrode system. A Pt wire was used as the counter electrode, a $\mathrm{Hg} / \mathrm{HgO}$ (4.24 M KOH solution) electrode and an $\mathrm{Ag} / \mathrm{AgCl}$ $(4.0 \mathrm{M} \mathrm{KCl})$ electrode were used as the reference electrodes in $0.1 \mathrm{M} \mathrm{KOH}$ and $0.1 \mathrm{M} \mathrm{HClO}_{4}$ electrolyte solutions, respectively. An RDE with a glassy carbon disk (5.0 $\mathrm{mm}$ diameter) and an RRDE electrode with a glassy carbon disk $(5.61 \mathrm{~mm}$ diameter) and a Pt ring $(6.25 \mathrm{~mm}$ inner diameter and $7.92 \mathrm{~mm}$ outer diameter were utilized as the substrates for the working electrode. The catalytic ink was prepared by dispersing $2.5 \mathrm{mg}$ catalyst powder in $500 \mu \mathrm{L}$ of a mixture solution containing $490 \mathrm{~mL}$ of ethanol and $10 \mu \mathrm{L}$ Nafion solution (5 wt\%) followed by ultrasonication for $2 \mathrm{~h}$. The ink was drop-cast on the disk electrode with a loading of $0.5 \mathrm{mg} \mathrm{cm}^{-2}$ to yield a uniform film electrode. CV was first carried out in $\mathrm{O}_{2}$-saturated electrolyte solution to activate the catalysts until the CV profile was stable. Then, the LSV polarization curves were recorded with a scan rate of $10 \mathrm{mV} \mathrm{s}^{-1}$ at different rotation speeds from 225 to $1600 \mathrm{rpm}$. The catalytic durability was investigated by an ADT test with $\mathrm{CV}$ under potentials from 0.6 to $1.0 \mathrm{~V}$ in the accelerated $\mathrm{O}_{2}$-saturated $0.1 \mathrm{M} \mathrm{KOH}$ or $0.1 \mathrm{M} \mathrm{HClO}_{4}$ electrolyte solution with a sweep rate of $50 \mathrm{mV} \mathrm{s}^{-1}$. The chronoamperometric measurement $(i-t)$ was carried out at $0.9 \mathrm{~V}$ in $0.1 \mathrm{M} \mathrm{KOH}$ electrolyte solution that was pre-saturated with oxygen for $25,000 \mathrm{~s}$ with a rotation rate of 1600 r.p.m. A commercial Pt/C ( $20 \mathrm{wt} \%$ $\mathrm{Pt}$, Fuelcellstore) was used for comparison with a Pt/C loading of $0.1 \mathrm{mg} \mathrm{cm}^{-2}$. The detailed analysis is provided in the Supplementary Materials.

Electrochemical HER measurements. The electrochemical HER performance of the M-SA-NSFC $(\mathrm{M}=\mathrm{Co}, \mathrm{Ru}$, Ir, and Pt) were evaluated using a RDE technique in an Ar-saturated $0.5 \mathrm{M} \mathrm{H}_{2} \mathrm{SO}_{4}$ solution. A graphite rod and an $\mathrm{Ag} / \mathrm{AgCl}(4.0 \mathrm{M} \mathrm{KCl})$ electrode were used as counter and reference electrode, respectively. The RDE with a catalyst loading of $0.5 \mathrm{mg} \mathrm{cm}^{-2}$ was used as working electrode. The HER polarization curves were collected from the potential range of 0 to approximately $-0.25 \mathrm{~V}$ (vs. RHE) at a scan rate of $2 \mathrm{mV} \mathrm{s}^{-1}$ and an electrode rotation speed of 1600 r.p.m.

Zn-air battery measurements. A home-built electrochemical cell was chosen to study the $\mathrm{Zn}$-air battery performance of the Fe-SA-NSFC. The catalytic ink was loaded on carbon fibre paper $\left(1 \mathrm{~cm}^{2}\right)$ with a loading density of $1 \mathrm{mg} \mathrm{cm}^{-2}$. This carbon fibre paper and polished $\mathrm{Zn}$ foil were used as the air cathode and anode, respectively. A 6.0 M KOH aqueous solution containing $0.2 \mathrm{M} \mathrm{Zn}(\mathrm{OAc})_{2}$ was employed as the electrolyte solution. All data were recorded from this cell on a Land CT2001A system at room temperature.

Computational methods. All theoretical calculations were performed using DFT with the CASTEP programme package in Materials Studio (version 2018), Accelrys, Inc. The Perdew-Burke-Ernzerhof (PBE) generalized gradient approximation (GGA) functional and ultrasoft pseudopotentials were employed to calculate the electronic exchange-correlation energies. The Grimme's DFT-D correction was adopted for the van der Waals interactions because of the failure of GGA/PBE functional to describe nonlocal dispersion force. The cut-off energy of the plane wave basis set was chosen to be $400 \mathrm{eV}$, and a $4 \times 4 \times 1$ Monkhorst-pack $k$-point grid over the Brillouin zone was used for the geometry optimization and energy calculations. The convergence criterion of energy was $10^{-5} \mathrm{Ha}$, the maximum force was $0.002 \mathrm{Ha} \AA^{-1}$ and the maximum displacement of $0.005 \AA$ of was used for all cases. The details are provided in the Supplementary Materials.

\section{Data availability}

The data that support the plots within this paper and other findings of this study are available from the corresponding author on reasonable request.

\section{Received: 17 May 2020; Accepted: 14 October 2020;}

Published online: 18 November 2020

\section{References}

1. Liu, L. C. \& Corma, A. Metal catalysts for heterogeneous catalysis: from single atoms to nanoclusters and nanoparticles. Chem. Rev. 118, 4981-5079 (2018)

2. Seh, Z. W. et al. Combining theory and experiment in electrocatalysis: insights into materials design. Science 355, eaad4998 (2017).

3. Chen, Y. J. et al. Single-atom catalysts: synthetic strategies and electrochemical applications. Joule 2, 1242-1264 (2018).

4. Gao, C. et al. Heterogeneous single-atom catalyst for visible-light-driven highturnover $\mathrm{CO}_{2}$ reduction: the role of electron transfer. Adv. Mater. 30, 1704624 (2018). 
5. Yang, X. F. et al. Single-atom catalysts: a new frontier in heterogeneous catalysis. Acc. Chem. Res. 46, 1740-1748 (2013).

6. Qiao, B. T. et al. Single-atom catalysis of $\mathrm{CO}$ oxidation using $\mathrm{Pt}_{1} / \mathrm{FeO}_{\mathrm{x}}$. Nat. Chem. 3, 634-641 (2011).

7. Xu, H. X., Cheng, D. J., Cao, D. P. \& Zeng, X. C. A universal principle for a rational design of single-atom electrocatalysts. Nat. Catal. 1, 339-348 (2018).

8. Wang, A. Q., Li, J. \& Zhang, T. Heterogeneous single-atom catalysis. Nat. Rev. Chem. 2, 65-81 (2018).

9. $\mathrm{Ju}, \mathrm{W}$. et al. Unraveling mechanistic reaction pathways of the electrochemical $\mathrm{CO}_{2}$ reduction on Fe-N-C single-site catalysts. ACS Energy Lett. 4, 1663-1671 (2019).

10. Cui, X. J., Li, W., Ryabchuk, P., Junge, K. \& Beller, M. Bridging homogeneous and heterogeneous catalysis by heterogeneous single-metal-site catalysts. Nat. Catal. 1, 385-397 (2018)

11. Sun, Y. Y. et al. Activity-selectivity trends in the electrochemical production of hydrogen peroxide over single-site metal-nitrogen-carbon catalysts. J. Am. Chem. Soc. 141, 12372-12381 (2019).

12. Zhang, Z. P., Sun, J. T., Wang, F. \& Dai, L. M. Efficient oxygen reduction reaction (ORR) catalysts based on single iron atoms dispersed on a hierarchically structured porous carbon framework. Angew. Chem. Int. Ed. 57, 9038-9043 (2018).

13. Pan, Y. et al. Regulating the coordination structure of single-atom $F e-N_{x} C_{y}$ catalytic sites for benzene oxidation. Nat. Commun. 10, 4290 (2019).

14. Ren, Y. J. et al. Unraveling the coordination structure-performance relationship in $\mathrm{Pt}_{1} / \mathrm{Fe}_{2} \mathrm{O}_{3}$ single-atom catalyst. Nat. Commun. 10, 4500 (2019).

15. Chung, H. T. et al. Direct atomic-level insight into the active sites of a highperformance PGM-free ORR catalyst. Science 357, 479-483 (2017).

16. Campbell, C. T. Catalyst-support interactions electronic perturbations. Nat. Chem. 4, 597-598 (2012).

17. O’Connor, N. J., Jonayat, A. S. M., Janik, M. J. \& Senftle, T. P. Interaction trends between single metal atoms and oxide supports identified with density functional theory and statistical learning. Nat. Catal. 1, 531-539 (2018).

18. Chen, G. B. et al. Zinc-mediated template synthesis of Fe-N-C electrocatalysts with densely accessible $\mathrm{Fe}-\mathrm{N}_{\mathrm{x}}$ active sites for efficient oxygen reduction. $A d v$. Mater. 32, 1907399 (2020).

19. Chen, Z. W., Chen, L. X., Yang, C. C. \& Jiang, Q. Atomic (single, double, and triple atoms) catalysis: frontiers, opportunities, and challenges. J. Mater. Chem. A 7, 3492-3515 (2019).

20. Zhang, J. et al. Cation vacancy stabilization of single-atomic-site $\mathrm{Pt}_{1} / \mathrm{Ni}(\mathrm{OH})_{\mathrm{x}}$ catalyst for diboration of alkynes and alkenes. Nat. Commun. 9, 1002 (2018).

21. Wan, J. W. et al. Defect effects on $\mathrm{TiO}_{2}$ nanosheets: Stabilizing single atomic site Au and promoting catalytic properties. Adv. Mater. 30, 1705369 (2018).

22. Lang, R. et al. Non defect-stabilized thermally stable single-atom catalyst. Nat. Commun. 10, 234 (2019).

23. Yang, M. et al. Catalytically active $\mathrm{Au}-\mathrm{O}(\mathrm{OH})_{\mathrm{x}}$-species stabilized by alkali ions on zeolites and mesoporous oxides. Science 346, 1498-1501 (2014).

24. Sun, Q. M. et al. Zeolite-encaged single-atom rhodium catalysts: highlyefficient hydrogen generation and shape-selective tandem hydrogenation of nitroarenes. Angew. Chem. Int. Ed. 58, 18570-18576 (2019).

25. Wang, X. X. et al. Nitrogen-coordinated single cobalt atom catalysts for oxygen reduction in proton exchange membrane fuel cells. Adv. Mater. 30, 1706758 (2018).

26. Wang, J. et al. Design of N-coordinated dual-metal sites: a stable and active Ptfree catalyst for acidic oxygen reduction reaction. J. Am. Chem. Soc. 139, 17281-17284 (2017)

27. Zhang, H. G. et al. Single atomic iron catalysts for oxygen reduction in acidic media: particle size control and thermal activation. J. Am. Chem. Soc. 139, 14143-14149 (2017)

28. Deng, J. et al. Triggering the electrocatalytic hydrogen evolution activity of the inert two-dimensional $\mathrm{MoS}_{2}$ surface via single-atom metal doping. Energy Environ. Sci. 8, 1594-1601 (2015).

29. Wang, L. et al. A sulfur-tethering synthesis strategy toward high-loading atomically dispersed noble metal catalysts. Sci. Adv. 5, eaax6322 (2019).

30. Cheng, Y. et al. Atomically dispersed transition metals on carbon nanotubes with ultrahigh loading for selective electrochemical carbon dioxide reduction. Adv. Mater. 30, 1706287 (2018).

31. Li, J. Z. et al. Atomically dispersed manganese catalysts for oxygen reduction in proton-exchange membrane fuel cells. Nat. Catal. 1, 935-945 (2018).

32. He, Y. H. et al. Highly active atomically dispersed $\mathrm{CoN}_{4}$ fuel cell cathode catalysts derived from surfactant-assisted MOFs: carbon-shell confinement strategy. Energ. Environ. Sci. 12, 250-260 (2019).

33. Peng, P. et al. A pyrolysis-free path toward superiorly catalytic nitrogencoordinated single atom. Sci. Adv. 5, eaaw2322 (2019).

34. Liu, S. et al. Soft-template construction of $3 \mathrm{D}$ macroporous polypyrrole scaffolds. Small 13, 1604099 (2017).

35. Liu, S. H. et al. Patterning two-dimensional free-standing surfaces with mesoporous conducting polymers. Nat. Commun. 6, 8817 (2015).
36. Zhao, L. et al. Cascade anchoring strategy for general mass production of high loading single-atomic metal-nitrogen catalysts. Nat. Commun. 10, 1278 (2019).

37. $\mathrm{Li}, \mathrm{Q}$. H. et al. Fe isolated single atoms on $\mathrm{S}, \mathrm{N}$ codoped carbon by copolymer pyrolysis strategy for highly efficient oxygen reduction reaction. Adv. Mater. 30, 1800588 (2018)

38. Qie, L. et al. Sulfur-doped carbon with enlarged interlayer distance as a high performance anode material for sodium-ion batteries. Adv. Sci. 2, 1500195 (2015).

39. Sun, X. J. et al. Fluorine-doped carbon blacks: highly efficient metal-free electrocatalysts for oxygen reduction reaction. ACS Catal. 3, 1726-1729 (2013).

40. Liu, Y. W. et al. A general strategy for fabricating isolated single metal atomic site catalysts in Y zeolite. J. Am. Chem. Soc. 141, 9305-9311 (2019).

41. Zhao, H. Y. et al. Carbon for the oxygen reduction reaction: a defect mechanism. J. Mater. Chem. A 3, 11736-11739 (2015).

42. Chen, Y. J. et al. Enhanced oxygen reduction with single-atomic-site iron catalysts for a zinc-air battery and hydrogen-air fuel cell. Nat. Commun. 9, 5422 (2018).

43. Ratso, S. et al. Effect of ball-milling on the oxygen reduction reaction activity of iron and nitrogen co-doped carbide-derived carbon catalysts in acid media. ACS Appl. Energ. Mater. 2, 7952-7962 (2019).

44. Ratso, S. et al. Synthesis of highly-active Fe-N-C catalysts for PEMFC with carbide-derived carbons. J. Mater. Chem. A 6, 14663-14674 (2018).

45. Zitolo, A. et al. Identification of catalytic sites for oxygen reduction in ironand nitrogen-doped graphene materials. Nat. Mater. 14, 937-942 (2015).

46. Miao, Z. P. et al. Atomically dispersed $\mathrm{Fe}-\mathrm{N}_{\mathrm{x}} / \mathrm{C}$ electrocatalyst boosts oxygen catalysis via a new metal-organic polymer supramolecule strategy. Adv. Energy Mater. 8, 1801226 (2018).

47. Chen, P. Z. et al. Atomically dispersed iron-nitrogen species as electrocatalysts for bifunctional oxygen evolution and reduction reactions. Angew. Chem. Int. Ed. 56, 610-614 (2017).

48. Zheng, Y. et al. Rational design of common transition metal-nitrogen-carbon catalysts for oxygen reduction reaction in fuel cells. Nano Energy 30, 443-449 (2016).

49. Xiao, M. L. et al. Climbing the apex of the ORR volcano plot via binuclear site construction: electronic and geometric engineering. J. Am. Chem. Soc. 141, 17763-17770 (2019)

50. Zhu, G. Q., Liu, F., Wang, Y. C., Wei, Z. D. \& Wang, W. Systematic exploration of N,C coordination effects on the ORR performance of $\mathrm{Mn}-\mathrm{N}_{\mathrm{x}}$ doped graphene catalysts based on DFT calculations. Phys. Chem. Chem. Phys. 21, 12826-12836 (2019).

51. Tang, C., Wang, B., Wang, H. F. \& Zhang, Q. Defect engineering toward atomic Co- $\mathrm{N}_{\mathrm{x}}-\mathrm{C}$ in hierarchical graphene for rechargeable flexible solid $\mathrm{Zn}$-air batteries. Adv. Mater. 29, 1703185 (2017).

52. Pan, Y. et al. A bimetallic $\mathrm{Zn} / \mathrm{Fe}$ polyphthalocyanine-derived single-atom Fe$\mathrm{N}_{4}$ catalytic site: a superior trifunctional catalyst for overall water splitting and Zn-air batteries. Angew. Chem. Int. Ed. 57, 8614-8618 (2018).

53. Yang, J. et al. In-situ cobalt and nitrogen doped mesoporous graphitic carbon electrocatalyst via directly pyrolyzing hyperbranched cobalt phthalocyanine for hydrogen evolution reaction. Electrochim. Acta 262, 48-56 (2018).

54. Liang, $\mathrm{H}$. W. et al. Molecular metal- $\mathrm{N}_{\mathrm{x}}$ centres in porous carbon for electrocatalytic hydrogen evolution. Nat. Commun. 6, 7992 (2015).

55. Cao, L. L. et al. Identification of single-atom active sites in carbon-based cobalt catalysts during electrocatalytic hydrogen evolution. Nat. Catal. 2, 134-141 (2019)

56. Pan, Y. et al. Core-shell ZIF-8@ZIF-67-derived CoP nanoparticle-embedded $\mathrm{N}$-doped carbon nanotube hollow polyhedron for efficient overall water splitting. J. Am. Chem. Soc. 140, 2610-2618 (2018).

57. Creus, J. et al. Ruthenium nanoparticles supported on carbon microfibers for hydrogen evolution electrocatalysis. Eur. J. Inorg. Chem. 2019, 2071-2077 (2019).

58. Bernsmeier, D. et al. Outstanding hydrogen evolution performance of supported Pt nanoparticles: incorporation of preformed colloids into mesoporous carbon films. J. Catal. 369, 181-189 (2019).

59. Li, F. et al. Balancing hydrogen adsorption/desorption by orbital modulation for efficient hydrogen evolution catalysis. Nat. Commun. 10, 4060 (2019).

60. Li, J. C. et al. Synergistic effect of ultrafine nano-Ru decorated cobalt carbonate hydroxides nanowires for accelerated alkaline hydrogen evolution reaction. Electrochim. Acta 331, 135367 (2020)

61. $\mathrm{Li}, \mathrm{Z}$. et al. In situ formed $\mathrm{Pt}_{3} \mathrm{Ti}$ nanoparticles on a two-dimensional transition metal carbide (MXene) used as efficient catalysts for hydrogen evolution reactions. Nano Lett. 19, 5102-5108 (2019).

62. Jiang, K. et al. Single platinum atoms embedded in nanoporous cobalt selenide as electrocatalyst for accelerating hydrogen evolution reaction. Nat. Commun. 10, 1743 (2019)

\section{Acknowledgements}

We thank the financial support from the Max Planck Society and Horizon 2020 research and innovation programme GrapheneCore2 (785219), Y.Z. and J.Y. thank the Natural Science Foundation of China (51672112, 51702129, and 51972150). Y.Z. acknowledges 
the support from the Postdoctoral Science Foundation (2018M630527) and Young Talents Program of Jiangsu University. Y.Z. and G.C. thank the China Scholarship Council for financial support (201708320150 and 201606970028). X.T. thanks the scholarship from Jiangsu University.

\section{Author contributions}

K.M., A.N., and Y.Z. conceived and designed the experiments. Y.Z. and X.T. conducted the synthesis, characterization, and electrochemical measurements of catalysts. X.T., D.W., and Y.J. obtained the TEM, HRTEM, and HAADF-STEM results. M.C. and H.L. performed the EXAFS measurements of catalysts. G.C. tested the $\mathrm{Zn}$-air battery performance and analysed the data. X.F. rendered helpful discussions. R.-H.L., E.J., and Y. Zhao carried out computational studies. Y.Z., A.N., and K.M. co-wrote the paper. The research was supervised by A.N. and K.M. All authors discussed the results and commented on the manuscript

\section{Funding}

Open Access funding enabled and organized by Projekt DEAL.

\section{Competing interests}

The authors declare no competing interests.

\section{Additional information}

Supplementary information is available for this paper at https://doi.org/10.1038/s41467020-19599-8.
Correspondence and requests for materials should be addressed to A.N. or K.M.

Peer review information Nature Communications thanks the anonymous reviewers for their contributions to the peer review of this work. Peer review reports are available.

Reprints and permission information is available at http://www.nature.com/reprints

Publisher's note Springer Nature remains neutral with regard to jurisdictional claims in published maps and institutional affiliations.

\section{(c) (1)}

Open Access This article is licensed under a Creative Commons Attribution 4.0 International License, which permits use, sharing, adaptation, distribution and reproduction in any medium or format, as long as you give appropriate credit to the original author(s) and the source, provide a link to the Creative Commons license, and indicate if changes were made. The images or other third party material in this article are included in the article's Creative Commons license, unless indicated otherwise in a credit line to the material. If material is not included in the article's Creative Commons license and your intended use is not permitted by statutory regulation or exceeds the permitted use, you will need to obtain permission directly from the copyright holder. To view a copy of this license, visit http://creativecommons.org/ licenses/by/4.0/.

(C) The Author(s) 2020 